The History of Sexually Transmittted Diseases. No 9 in a series edited by Milton Lewis and Michael Waugh.

\title{
The history of venereology in Norway
}

\author{
Ole Fyrand, Astri Granholt
}

\begin{abstract}
Syphilis became a problem at the beginning of the eighteenth century when a virulent microbe was brought to Norway. This new disease was called "radesyken", a Nordic name for "the wicked disease". "Rade" hospitals were built and this was the beginning of the Norwegian hospital system. Professor Caesar Boeck refused to use mercury in the treatment of syphilis; 2000 of his patients were included in the Oslo study of untreated syphilis. With the use of penicillin and other antibiotics, syphilis and gonorrhoea decreased. More frequent now are the viral diseases, herpes genitalis and condylomata acuminata. HIV is seldom found in the STD clinic in Oslo: only 5-6 HIV-positive persons per year; that is, about $0.09 \%$ of all new patients.
\end{abstract}

(Genitourin Med 1994;70:215-217)

\section{Introduction}

Before the turn of the last century dermatovenereological diseases were among the most prevalent in the Norwegian population. In the Middle Ages leprosy was a common disease, and in contrast to the rest of Europe, the incidence of leprosy increased in the 18th and the first part of the 19th century in Norway. After the start of the great European syphilis epidemic, following the siege of Naples by Charles VIII in 1494, syphilis appeared within a few years in Norway. In 1518 the "Franzosen-krankheit" is mentioned in the annals of the Hanseatic Norwegian town, Bergen.

\section{"Radesyken"-a virulent syphilis}

Syphilis was not a great problem in Norway until the 18th century, when a more virulent microbe was brought to Norway from abroad. In 1709 a Russian military vessel established winter quarters on the west coast close to the town of Stavanger. As a consequence of "conversation" between the local ladies and the crew, an unknown venereal disease (VD) spread in the population. Crews from other foreign ships infected Norwegians in other ports, and the resulting epidemic disseminated throughout the country, especially in the poor rural districts. The disease was called "radesyken", an old Nordic name for "the wicked disease".

This happened at a time when Norway was in union with Denmark, with the government located in Copenhagen, and when the country was geographically and administratively isolated. The few educated medical doctors in the large towns were not able to stop the plague. In 1763 a number of doctors were sent from Denmark in order to combat the disease in the patients' homes-an impossible enterprise owing to the poor social conditions. Consequently, a number of "rade" hospitals were built in different parts of Norway in the second half of the century; and this was the beginning of the Norwegian hospital system.

\section{Dermato-venereology as a separate hospital department}

After the first university was founded in 1811 in Oslo (the town was named Christiania between 1624 and 1924), dermato-venereology was taught in a "radehospital" outside the town as a subsection of medicine from 1817. In 1825, the patients were transferred to the national hospital, the Rikshospitalet, and in 1841 a separate dermato-venereological department was established in response to a royal decree emanating from Stockholm. From 1814 to 1905 , Norway was in union with Sweden.

The first chief of the department was Jens Johan Hjort (1789-1873), who had been in charge of the old dermato-venereological section from 1817. He continued as head of the hospital department until he resigned in 1871. Hjort worked with Carl Wilhelm Boeck (1808-1875), who was elected first professor in dermato-venereology, surgery and pathology in 1851. From 1871 to 1875 Boeck was also chief of the department.

Boeck's main interests were leprosy ${ }^{1}$ and "radesyke". He claimed that "radesyke" was caused by a "syphilitic virus" or "poison" and that conventional treatment of syphilis with mercury in inunctions (ointments), solutions, pills and fumigations had a disastrous effect upon the patient's physiological resistance to the disease. He therefore abstained from the use of mercury, and instead vaccinated ${ }^{2}$ patients with "constitutional syphilis" (syphilis in the second or third stage of the disease), using pus from veneral soft or hard chancres in order to stimulate the natural resistance of the organism, according to the modern vaccination therapy of Jenner. The originator of syphilisation was the French doctor, Auzias Turenne. ${ }^{3}$ In the period between 1852 and 1870 , Boeck treated 1075 patients with syphilisation at his clinic. This 
method was highly contentious in Europe, where the "dualistic" theory (generally accepted in 1860) postulated that the soft and hard chancre represented two different diseases, in contrast to the "unitarian" theory (amongst the followers of which Boeck could be found) which asserted that both were manifestations of syphilis.

\section{The visit of fonathan Hutchinson}

In 1869 Boeck was visited by a distinguished syphilologist from England, Jonathan Hutchinson (1828-1913), who wrote about his visit the same year. ${ }^{4}$ He came to substantiate his theory about the cause of leprosy, which he claimed was the result of the eating of decomposed fish. He observed entire families in Norway infected with "radesyken", and having open contagious syphilitic lesions as a result of living in close contact with each other, of sleeping in common beds and eating from the same utensils without washing them. He condemned strongly the practice of the venereological department in Oslo, whereby patients suspected of having syphilis were transported by the police from their homes to detention for months in the hospital ward. The ward had locked doors and was surrounded by barbed wire fences.

\section{Registration and inspection of prostitutes}

At that time in Oslo VD was seen as resulting from the activities of female prostitutes working in "official houses", who were supervised by "poor law" doctors. In 1860, the first law on infectious diseases was passed in Norway, and now prostitutes were supervised by police doctors, who issued official "visitation cards" to those free of VD. In 1887, prostitution was prohibited, the "official houses" closed, and "visitations" stopped, with a consequent increase of VD in Oslo.

From 1876, VD cases were reported in Oslo and from 1882 in other cities; and a national system of reporting was introduced in 1922. Until 1950, only two hospitals in Norway had separate departments for treatment of VD, the Rikshospitalet and the municipal hospital Ullevål, both located in Oslo.

The Oslo study of untreated syphilis

When CW Boeck died in 1875, syphilisation was abandoned at the clinic. His nephew, Caesar Boeck (1845-1917), was elected chief of the department. Caesar Boeck, ${ }^{5}$ who had won international fame for his description of sarcoidosis (Morbus Boeck) in 1899, retired in 1915. In the treatment of syphilitic patients, he followed his uncle's regime of not using mercury. With the intention of stimulating resistance, he treated in 1890-1910 approximately 2000 patients with roborant meals and rest until the syphilitic symptoms disappeared. In 1910 he started to use salvarsan and later neo-salvarsan.

Caesar Boeck was succeeded by Edvin Bruusgaard (1869-1934), who in 1925 investigated the well-kept records of Caesar Boeck. In the records, the lesions were described on admission, and their regression and time of disappearance noted. Bruusgaard ${ }^{6}$ wanted to show "how syphilis progresses when little or no treatment is given and the patient's defence mechanism is allowed to combat the disease alone". Because of a relatively limited number of patients ( $20 \%$ of 2181 patients), Caesar Boeck's patients were studied again at the dermatological department at the Rikshospitalet in 1948. The state of health of the living and the cause of death of those dead were investigated. Of 1978 original patients, $20 \%$ were randomly analysed, and the study showed that of those infected, $23.6 \%$ had experienced clinical secondary relapse, $15 \cdot 8 \%$ benign tertiary syphilis, $10 \cdot 4 \%$ cardiovascular syphilis, and $6.6 \%$ neurosyphilis. A total of $10 \%$ died of the disease ${ }^{7}$

\section{Gonorrhoea}

Gonorrhoea (blenorrhagia) cases were given non-specific remedies before sulphonamides ${ }^{8}$ were marketed. Females were treated with disinfecting rinses, cervical swabbing and sticks of silver nitrate, males with silver nitrate and potassium permanganate rinses; and urethral strictures were dilated with metal bougies.

The patients were hospitalised for months, and in order to prevent the spread of gonorrhoea during weekend leaves, on Saturday morning intramuscular injections of sulphur were often given, causing patients pain and fever. Men and women lived in separate rooms, each having 18 to 22 beds, and the department was surrounded by board fences and barbed wire until the 1930s. In 1968 the section for STD in Oslo started to use oral antibiotics against gonorrhoea. The first drug was pivampicillin, in the beginning combined with injections of other antibiotics and probenicid.

\section{The rise and fall of VD in Norway}

With the introduction of penicillin in 1947 syphilis had increased during and after the Second World War, with $1.4 \%$ of the Oslo population having VD-the prevalence of VD declined in the 1950 s to $0.15 \%$ of the population; $0.01 \%$ had syphilis. This prevalence was the lowest since registration of VD began more than 100 years earlier. In the 1960 s, the prevalence increased, especially among younger age groups: in $1960,0.315 \%$ and $1970,0.57 \%$. With the new sexual mores of the 1980s resulting from the HIV epidemic, the number of classical VD and other sexually transmitted diseases declined. At the STD clinic in Oslo, the number of new patient consultations was reduced from 10,454 in 1980 to 7,438 in 1991 (see table).

Table Sexually transmitted diseases, Oslo VD clinic, 1980-1991

\begin{tabular}{lrr}
\hline$S T D$ & \multicolumn{1}{c}{1980} & 1991 \\
\hline New patients & 10,454 & 7,438 \\
Gc & 2,241 & 104 \\
Syphilis & 40 & 5 \\
Chlamydia & 1,857 & 583 \\
Herpes & 385 & 278 \\
Condylomata & 818 & 695 \\
\hline
\end{tabular}


Chlamydia and viral infections

In the $1970 \mathrm{~s}$, the search for other microbes causing non-gonococcal urethritis started, revealing the causal relation to Chlamydia trachomatis in 1979. Routine screening of all patients at the STD clinic in Oslo was introduced in 1980 . In $1984-1985,25 \%$ of all men and $23 \%$ of all women harboured chlamydia microbes, compared with $8 \%$ in 1992. The prevalence of viral STD infections is now (1992) constant with $4 \%$ of the patients having genital herpes, and with human papilloma virus infections (condyloma acuminata) being the most prevalent STD in patients today (10\%). From 1985 all patients were invited to be tested for HIV, and in $85 \%$ this was done. During the last four years, 4-5 new cases have been found annually at the STD clinic; all cases were gay men or IVdrug abusers; they comprised $0 \cdot 1 \%$ of all new patients seen at the STD clinic in Oslo.

The unpredictable future of venereology

As in most countries, venereology in Norway is a sub-speciality of dermato-venereology. With the establishment of VD clinics in the three largest cities in Norway, the first in Oslo in 1935, venereology has gradually become alienated from dermatology. Because of the reduced incidence and prevalence of VD, venereology cases are no longer regularly seen by dermatologists in Norway.

Because there are few dermato-venereological specialists in Norway, patients with dermatological and venereological diseases primarily contact general practitioners (GPs). This is in accord with the official health policy, which aims to train GPs to diagnose, treat and prophylactically combat infectious diseases. In larger cities, STD clinics have in the last few years registered persons at risk, especially for HIV infections. In Oslo a section for AIDS prevention has worked exclusively on HIV problems.

The venereology of the future is developing a new approach in which doctors, nurses and other health workers focus on prophylactic work, in a time dominated by viral infections for which there are no effective treatments. In Oslo a new combined organisation is planned which will bring together the dermatological department at Ulleval Hospital and the Sections for STD and for AIDS Prevention of the Oslo City Department of Health and Environment. This may result in a new alliance between dermatology and venereology, and serve as a source for future dermatovenereological concepts in Norway.

Roar Bjornstad, Emeritus Professor and former chief of the Dermatological Department, Oslo Municipal Hospital Ullevål, and Tor Gundersen MD, former chief of the Section for STD, Oslo City Department of Health and Environment, provided invaluable information for the paper.

Danielsen CD, Boeck CW. Atlas collorie de spedalskhed. (Elephantiasis des Grecs). Bergen en Norvège, 1847.

2 Boeck W. Recherches sur la syphilis. Christania, H J Jensen, 1862.

3 Turenne A. La Syphilisation Paris, 1878.

4 Hutchinson J. Norwegian Notes. In: The Medical Times $\mathcal{E}$ Gazette, 1869.

5 Boeck C. Multiple benign sarkoid of the skin. F. Cutan Genitourin Dis, 1899;17:543-50.

6 Bruusgaard E. Uber das Schicksal der nicht spezifisch behandelten Luetiker. Arch Dermatol Syph, 1929; behandelten

7 Gjestland T. The Oslo Study of Untreated Syphilis. Acta Dermato-Venereol (Stock), 1955;Suppl. 34, vol. 35.

8 Bjørnstad R. Sulfonamider og Antibiotica i Dermatovenereologien. In: Vogt JH ed, Sulfonamider og Antibiotica, Oslo, 1949. 98-104 